\title{
Combining interface damage and friction in cohesive interface models using an energy based approach
}

DOI:

10.1016/j.compositesa.2018.06.017

\section{Document Version}

Accepted author manuscript

Link to publication record in Manchester Research Explorer

\section{Citation for published version (APA):}

Zou, Z., \& Hameed, M. (2018). Combining interface damage and friction in cohesive interface models using an energy based approach. Composites Part A: Applied Science and Manufacturing, 112.

https://doi.org/10.1016/j.compositesa.2018.06.017

\section{Published in:}

Composites Part A: Applied Science and Manufacturing

\section{Citing this paper}

Please note that where the full-text provided on Manchester Research Explorer is the Author Accepted Manuscript or Proof version this may differ from the final Published version. If citing, it is advised that you check and use the publisher's definitive version.

\section{General rights}

Copyright and moral rights for the publications made accessible in the Research Explorer are retained by the authors and/or other copyright owners and it is a condition of accessing publications that users recognise and abide by the legal requirements associated with these rights.

\section{Takedown policy}

If you believe that this document breaches copyright please refer to the University of Manchester's Takedown Procedures [http://man.ac.uk/04Y6Bo] or contact uml.scholarlycommunications@manchester.ac.uk providing relevant details, so we can investigate your claim.

\section{OPEN ACCESS}




\title{
Combining interface damage and friction in cohesive interface
}

\section{models using an energy based approach}

\author{
Zhenmin Zou*, Marwah Hameed \\ School of Mechanical, Aerospace and Civil Engineering, The University of Manchester, \\ Manchester M13 9PL, UK
}

\begin{abstract}
Cohesive zone models coupling interface damage and friction have been developed in the literature and are available in the commercial finite element package ABAQUS to consider the enhancing effect of through-thickness compression on interfacial fracture resistance. It is revealed in this paper that these models are extremely dependent on interface stiffness, because interface stiffness reduction factor is used to combine damage and friction in these models. The interfacial constitutive law converges but only when the interface is extremely stiff and an unrealistic evolution of the interface damage is produced. A new approach is then developed which uses a cohesive energy related parameter to combine interface damage and friction. The behaviour of the new coupled model is independent of the interface stiffness once the interface is moderately stiff. The new and existing damage/friction coupled models have been employed to simulate the shear failure of a composite specimen and the predictions are compared against the experimental data in the literature. The new model produces converged results over a wide range of interface stiffness and the predictions match the experiments quite well, better than the existing models.
\end{abstract}

KEY WORDS: Cohesive zone model; interface element model; interface damage and friction coupling; interface stiffness dependence.

\footnotetext{
* Corresponding author: z.zou@manchester.ac.uk
} 


\section{Introduction}

Cohesive zone model is one of the most popular tools for simulating damage in composite structures, such as delamination [1, 2], fibre/matrix debonding [3] and adhesive bonding joint failure [4]. In most of the existing cohesive zone models, the effect of throughthickness stress on damage initiation and growth is ignored when the interface is under compression. However, experiments have shown that through-thickness compression increases both the interlaminar shear strength [5] and mode II fracture energy [6]. Excluding this effect will produce an inaccurate prediction of interlaminar damage in composite structures. The direct effect of the through thickness compression is the contact/friction in the damaged interface area. Sitnikova et al. [7] simulated delamination in a laminate subjected to low velocity impact. It was revealed that friction in the delaminated area must be considered in order to capture the intact zone underneath the impactor as commonly observed in experiments.

Tvergaard [3] was the first to introduce friction into the cohesive zone model, but the frictional stress was included only when total decohesion had occurred. On the other hand, some researchers proposed to activate frictional stress in the cohesive zone model from the very beginning of the decohesion process [8]. To achieve a continuous and smooth transition from decohesion to a pure friction state explicitly, a predefined function was used to regulate the addition of frictional stress to the interface shear traction $[9,10]$.

Effort has been made to include friction in cohesive zone model naturally. Based on a meso-mechanical approach, Alfano and Sacco [11] divided a representative elementary area of the interface into a damaged part and an integral part. The relative measure of the damaged area was defined as the damage parameter and friction was assumed to take place only in the damaged part. The classical rule of mixture was then used to combine the contributions from the integral and damaged parts, and so the constitutive law of the interface was established. A 
seamless transition from pure cohesive behaviour to a purely frictional one is achieved during the damaging process. Similar concept of interface damage/friction coupling has been adopted by the commercial finite element package ABAQUS. A surface-based cohesive contact model is available in ABAQUS [12] in which the cohesive traction separation behaviour is defined as a surface interaction property between a contact pair of surfaces.

Issues arose when the above damage/friction coupled cohesive models in [11, 12] were employed to simulate interfacial damage in composites. Alfano and Sacco [11] conducted an interface stiffness sensitivity study when modelling a fibre push out test. The results are nearly independent of the stiffness but only for an extremely stiff interface. It is well known that the traditional cohesive zone model (i.e. those without damage-friction coupling) produces converged results once the interface stiffness is moderately high, not extremely high. The guidelines for choosing the interface stiffness is that it should be high enough to provide a sufficient connection but low enough to avoid the risk of numerical problem [13]. An excessively stiff interface will cause numerical ill condition. Using the surface-based cohesive model in ABAQUS, Zhang and Zhang [14] simulated delamination in a composite laminate. Their investigation showed that an input of a high friction coefficient, greater than 0.6 , is required in order to match the prediction with the experiment, although friction coefficients of similar material measured in other experiment are less than 0.6 [15].

The interface damage/friction coupling method proposed in [11] has been increasingly employed in cohesive zone models by others [16-19]. More and more researchers have used the surface-based cohesive contact model in ABAQUS [12] to simulate damage in composite materials and structures [14, 20-22]. There is an urgent need to address the issues encountered by this type of damage/friction coupling in cohesive zone models.

The present study aims to develop a new approach to combine damage and friction naturally in cohesive interface models, but avoid the drawback of the existing damage/friction 
coupled models in $[11,12]$. The behaviour of the cohesive zone model in [11] and the surface-based cohesive model in ABAQUS [12] are first analysed to identify the reason behind their extreme dependence on interface stiffness. A new method is then proposed to combine damage and friction in the cohesive model more properly. Finally, the new and existing coupled models are employed to simulate the shear failure of a composite specimen. Predictions are compared against the experimental data in the literature to demonstrate the success of the new method and the advantage of it over the existing approach in $[11,12]$.

\section{The existing damage/friction coupling method in cohesive zone models}

Combining damage and friction in the cohesive zone model was first proposed by Alfano and Sacco [11]. For simplicity, only the formulation of the model under through-thickness compression is summarised and presented in this section. Based on a meso-mechanics method, a unit representative elementary area (REA) of the interface is partitioned into two parts, a damaged part of an area $\omega$ and an undamaged part of an area $(1-\omega)$ as shown in Fig.

1. Friction is assumed to only take place in the damaged part. The relationship between the tractions $\tau_{i}$ and separations $\delta_{i}(i=1,2)$ of the interface is then expressed as

$$
\begin{aligned}
& \tau_{1}=k_{1} \delta_{1} \\
& \tau_{2}=(1-\omega) k_{2} \delta_{2}+\omega \tau_{f}
\end{aligned}
$$

where subscripts 1 and 2 represent the normal and shear directions, respectively. $k_{i}$ is the cohesive stiffness of the interface. $\tau_{f}$ is the frictional stress which is obtained by

$$
\begin{array}{ll}
\tau_{f}=k_{2}\left(\delta_{2}-\delta_{s}\right) & \text { if } k_{2}\left|\delta_{2}-\delta_{s}\right|+\mu \tau_{1}<0, \text { sticking occurs } \\
\tau_{f}=-\mu \tau_{1} \frac{\delta_{2}-\delta_{s}}{\left|\delta_{2}-\delta_{s}\right|} & \text { if } k_{2}\left|\delta_{2}-\delta_{s}\right|+\mu \tau_{1} \geq 0 \text {, sliding takes place }
\end{array}
$$

where $\mu$ is the coefficient of friction and $\delta_{s}$ is a frictional sliding displacement. $\delta_{s}$ is zero initially and is updated in the following incremental form 


$$
\begin{array}{ll}
d \delta_{s}=0 & \text { when } k_{2}\left|\delta_{2}-\delta_{s}\right|+\mu \tau_{1}<0 \\
d \delta_{s}=\left(\left|\delta_{2}-\delta_{s}\right|+\frac{\mu \tau_{1}}{k_{2}}\right) \times \frac{\delta_{2}-\delta_{s}}{\left|\delta_{2}-\delta_{s}\right|} & \text { when } k_{2}\left|\delta_{2}-\delta_{s}\right|+\mu \tau_{1}>0
\end{array}
$$

The shear traction $\tau_{2}$ on the interface in equation (1b) is the sum of the cohesive shear stress $\widetilde{\tau}_{2}=(1-\omega) k_{2} \delta_{2}$ and the contribution of frictional stress $\tau_{f^{\prime}}$. Friction and cohesive damage are coupled by the term $\omega \tau_{f}$.

The damage parameter $\omega$ in the constitutive equation (1) defines the effective cohesive stiffness $(1-\omega) k_{2}$ of the interface. When the bilinear cohesive traction-separation law as shown in Fig. 1 is employed, the damage evolution law is expressed as

$$
\omega=\max _{\text {history }} \widetilde{\omega} \quad \text { and } \quad \widetilde{\omega}=\max \left\{0, \min \left\{1, \frac{\delta_{2 f}\left(\delta_{2}-\delta_{2 o}\right)}{\delta_{2}\left(\delta_{2 f}-\delta_{2 o}\right)}\right\}\right\}
$$

where $\delta_{2 o}$ and $\delta_{2 f}$ are separations at damage initiation and full damage, respectively. They are related to the interface shear strength $\tau_{2 c}$ and mode II fracture energy $G_{2 c}$ as follows

$$
\delta_{2 o}=\tau_{2 c} / k_{2} \quad \text { and } \quad \delta_{2 f}=2 G_{2 c} / \tau_{2 c}
$$

It can be seen in Fig. 1 that the ratio between $\delta_{2 o}$ and $\delta_{2 f}$ defines the shape of the bilinear cohesive law. Because $\delta_{2 o}$ depends on the initial stiffness $k_{2}$ of the interface, a method is proposed in the present paper to describe how stiff an interface is. The interface is considered as: (a) extremely stiff if $\delta_{2 o} / \delta_{2 f} \leq 0.001$; (b) stiff when $0.001<\delta_{2 o} / \delta_{2 f} \leq 0.01$; (c) moderately stiff in the case of $0.01<\delta_{2 o} / \delta_{2 f} \leq 0.05$; (d) weak if $0.05<\delta_{2 o} / \delta_{2 f} \leq 0.25$; and (e) very weak when $0.25<\delta_{2 o} / \delta_{2 f}$.

In the present work, the behaviour of the above damage/friction coupled interface model under through thickness compression was investigated, using the interface properties given in Table 1. Different values of the initial interface stiffness $k_{2}$ were attempted. A constant 
compressive through thickness stress $\tau_{1}$ was assigned and the interface was loaded by increasing the shear separation $\delta_{2}$ monotonically.

When friction is excluded (by setting $\mu=0$ ), this interface model reproduces the bilinear traction-separation relationship shown in Fig. 2 as expected. It can be seen that changing interface stiffness $k_{2}$ only changes the separation $\delta_{2 o}$ at damage initiation as indicated in equation (5). The two most important parameters of the cohesive zone model, peak shear traction and the area under the curve, remain unchanged. However, when friction is included $(\mu=0.26), k_{2}$ has a significant effect on the behaviour of the interface. The increase of $k_{2}$ raises the shear traction during the entire interface damaging process. Both the peak shear traction and the area under the curve keep increasing as the interface becomes stiffer and stiffer. The curves converge when $k_{2}$ reaches extremely high values.

The damage parameter and shear stress during the damaging process $\left(\delta_{2 o} \leq \delta_{2} \leq \delta_{2 f}\right)$ can be derived from equations (1), (4) and (5) as

$$
\omega=\frac{1-\tau_{2 c} / k_{2} \delta_{2}}{1-\tau_{2 c} / k_{2} \delta_{2 f}} \quad \text { and } \quad \tau_{2}=\frac{\delta_{2 f}-\delta_{2}}{\delta_{2 f}-\delta_{2 o}} \tau_{2 c}+\omega \tau_{f}
$$

Obviously, $\omega$ depends on the initial interface stiffness $k_{2}$. The dependence is significant as shown by the damage evolution curves in Fig. 3. A weak interface produces a steady damage evolution. For a moderately stiff interface, $\omega$ increases rapidly after damage initiation and then slows down gradually until it reaches unity. If a very stiff interface is used, $\omega$ climbs sharply to a value very close to unity, resulting in a flat line in most of the damaging process. The damage evolution curves converge when the interface is extremely stiff.

Since the contribution of the frictional stress to the shear stress on the interface is in proportion to $\omega$, the shear stress-sliding separation curve becomes extremely sensitive to $k_{2}$. The converged shear stress takes an approximate form of $\tau_{2}=\left(1-\delta_{2} / \delta_{2 f}\right) \tau_{2 c}+\tau_{f}$.

A simple finite element model, consisting of two solid elements connected by a surface- 
based cohesive interface, was also created in ABAQUS to check the behaviour of the surfacebased cohesive contact model in ABAQUS. Almost identical results to those presented above were obtained. There is no formulation available in the ABAQUS manual and how the model works is described in the manual as follows [12]. If the interface is under tension, only the cohesive behaviour is active. When the interface is under compression, the conventional pressure overclosure relationship governs the contact behaviour in the normal direction and the cohesive model makes no contribution to the normal stress. In the shear direction, the cohesive model is active and the friction model activates once cohesive damage initiates. The frictional stress is added to the cohesive shear stress to obtain the total shear stress. The elastic stiffness of the friction model is assumed to climb up in proportion to the reduction of the cohesive stiffness. The cohesive model loses its stiffness completely and contributes nothing to the shear stress after it is fully damaged. It is clear that this surface-based cohesive contact model in ABAQUS uses a coupling method similar to that in the cohesive interface model in [11] in principle.

The damage parameter $\omega$ in the traction-separation law in equation (1) works as the cohesive stiffness reduction factor. Traditionally, the initial stiffness of the cohesive interface is regarded as the constraint/penalty stiffness and its value is not unique as long as it is high enough. Due to the arbitrariness of the initial interface stiffness, the cohesive stiffness reduction factor should not be used to represent the damaged area in the REA of the interface. Otherwise, for a stiff interface, almost all of the REA will reach a damaged state very quickly after the damage initiation as shown in Fig. 3. Such growth of the damaged area in the REA is physically unacceptable. Friction would make an unrealistic over contribution to the shear traction of the interface during the decohesion process according to equation (1b). A new parameter, rather than the cohesive stiffness reduction factor, is therefore needed to describe the area of the damaged part in the REA of the interface for a better combination of damage 
and friction in the cohesive interface model.

\section{New approach to combine damage and friction in cohesive interface model}

Zou and Lee [18] developed a cohesive interface model which considers the effect of through thickness compression on the interfacial shear resistance. Since they followed Alfano and Sacco's method [11] to combine damage and friction, that model has the interface stiffness dependence issue as well. The work presented in this section is a further development to the model in [18]. Firstly, an enhanced mode II cohesive fracture energy is employed to improve the model. Secondly, and more importantly, a new method is proposed to combine damage and friction based on the energy concept in fracture mechanics to avoid the interface stiffness dependence issue. The improved cohesive interface model and how to couple damage and friction are described below.

The cohesive tractions $\widetilde{\tau}_{i}$ are related to the separations $\delta_{i}$ as

$$
\begin{array}{ll}
\widetilde{\tau}_{1}=k_{1} \delta_{1} & \text { when } \delta_{1}<0 \\
\widetilde{\tau}_{1}=(1-\omega) k_{1} \delta_{1} & \text { when } \delta_{1}>0 \\
\widetilde{\tau}_{2}=(1-\omega) k_{2} \delta_{2} &
\end{array}
$$

The experiments in $[5,6]$ show that compressive through thickness stress enhances the interfacial shear resistance. Effort has been made to consider this enhancing effect in the literature. Compressive stress was included in stress-based criteria for damage initiation [23, 24]. Enhanced cohesive shear strength and mode II fracture energy were proposed by Li et al. [25] as follows for assessing cohesive damage initiation and propagation

$$
\begin{aligned}
& \tau_{2 c n}=\tau_{2 c}\left(1+\eta\left\langle-\widetilde{\tau}_{1}\right\rangle / \tau_{2 c}\right) \\
& G_{2 c n}=G_{2 c}\left(1+\eta\left\langle-\tau_{1}\right\rangle / \tau_{2 c}\right)
\end{aligned}
$$

where $\langle\cdots\rangle$ is the Macauley operator defined as: $\langle x\rangle=x$ if $x \geq 0$ and $\langle x\rangle=0$ if $x<0 . \tau_{2 c}$ and $G_{2 c}$ are the conventional cohesive shear strength and mode II fracture energy of the cohesive 
interface, respectively, when there is no through thickness compression. $\eta$ is an enhancement factor which is a material property as well.

The quadratic stress-based failure function proposed by Li et al. [25] is employed for predicting cohesive damage initiation

$$
f_{s}=\left(\frac{\left\langle\widetilde{\tau}_{1}\right\rangle}{\tau_{1 c}}\right)^{2}+\left(\frac{\tilde{\tau}_{2}}{\tau_{2 c n}}\right)^{2}
$$

where $\tau_{1 c}$ is the cohesive tensile strength.

Cohesive damage initiates when $f_{s}$ reaches unity. Further loading makes the cohesive damage grow. In order to assess when the cohesive interface reaches a full decohesion state, the following energy rates by the mode I and mode II cohesive tractions are defined

$$
\begin{aligned}
& G_{1}=\int_{0}^{\delta_{1}} \widetilde{\tau}_{1} d \delta_{1} \\
& G_{2}=\int_{0}^{\delta_{2}} \frac{\widetilde{\tau}_{2}}{1+\eta\left\langle-\widetilde{\tau}_{1}\right\rangle / \tau_{2 c}} d \delta_{2}
\end{aligned}
$$

Complete decohesion takes place when the following fracture-mechanics-based mixed mode linear failure function $f_{g}$ reaches unity

$$
f_{g}=\frac{G_{1}-G_{1 o}}{G_{1 c}-G_{1 o}}+\frac{G_{2}-G_{2 o}}{G_{2 c}-G_{2 o}}
$$

where $G_{1 c}$ is the mode I cohesive fracture energy. $G_{1 o}$ and $G_{2 o}$ are mode I and mode II energy rates at damage initiation when $f_{s}=1$ is first met. When the interface is under through thickness compression, the contribution from mode I is excluded from equation (12).

$G_{2}$ as defined in equation (11b) is a reduced mode II energy rate for a convenient introduction of the enhancing effect of through-thickness compression on mode II fracture energy. Under pure mode II loading, cohesive failure completes when $G_{2}=G_{2 c}$ according to the failure condition $f_{g}=1$ in equation (12). This means that the energy dissipation $\int_{0}^{\delta_{2 f}} \widetilde{\tau}_{2} d \delta_{2}$ 
by the cohesive shear traction during the entire decohesion process equals $G_{2 c}\left(1+\eta\left\langle-\widetilde{\tau}_{1}\right\rangle / \tau_{2 c}\right)$. Therefore, increased mode II fracture energy is implemented in the model when the interface is under through thickness compression. This increased fracture energy is the same as the enhanced mode II fracture energy $G_{2 c n}$ in equation (9) proposed by Li et. al [25].

To construct a softening traction-separation law, a single failure criterion is used [18]

$$
F\left(\widetilde{\tau}_{i}, G_{i}\right)=f_{s}+f_{g}=\left(\frac{\left\langle\widetilde{\tau}_{1}\right\rangle}{\tau_{1 c}}\right)^{2}+\left(\frac{\widetilde{\tau}_{2}}{\tau_{2 c n}}\right)^{2}+\frac{G_{1}-G_{1 o}}{G_{1 c}-G_{1 o}}+\frac{G_{2}-G_{2 o}}{G_{2 c}-G_{2 o}}=1
$$

Before damage initiation, $f_{g}$ is set to be zero. The failure function $F$ in equation (13) equals $f_{s}$ and the criterion is a stress-based criterion for damage initiation. After damage initiates at $f_{s}=1$, further loading makes the damage grow. $f_{g}$ then increases, and $f_{s}$ decreases according to equation (13). Consequently, cohesive tractions are reduced as separations increase. Finally, the cohesive tractions are automatically reduced to zero when the fracturemechanics based failure function $f_{g}$ reaches unity.

It should be pointed out that $G_{1}$ and $G_{2}$ are not the mode I and mode II cohesive energy release rates before full decohesion is reached. They become the energy release rates at complete decohesion and are used to assess whether decohesion has finished. $G_{1}$ and $G_{2}$ also play an important role in constructing the bilinear cohesive traction-separation law. It can be proved that if the tractions and energy rates are determined from the conventional bilinear traction-separation law under pure mode I or mode II, then equation (13) will be satisfied.

Damage growth in structures is an irreversible non-linear process and usually, an incremental procedure is required for solution. Assuming separations are increased incrementally by $d \delta_{i}$, cohesive tractions $\tilde{\tau}_{i}$ and energy rates $G_{i}$ can then be calculated using equations (7) and (11), respectively, while the damage parameter $\omega$ is kept unchanged 
temporarily. After this, the failure function $F\left(\widetilde{\tau}_{i}, G_{i}\right)$ is checked. If $F\left(\widetilde{\tau}_{i}, G_{i}\right)<1$, there will be no damage initiation or growth, $d \omega=0$.

When $F\left(\widetilde{\tau}_{i}, G_{i}\right) \geq 1$, damage initiates or grows. Cohesive tractions $\widetilde{\tau}_{i}$ and energy rates $G_{i}$ need to satisfy the condition $F\left(\widetilde{\tau}_{i}, G_{i}\right)=1$. Therefore

$$
d F=\sum_{i=1}^{2} \frac{\partial F}{\partial \widetilde{\tau}_{i}} d \widetilde{\tau}_{i}+\sum_{i=1}^{2} \frac{\partial F}{\partial G_{i}} d G_{i}=0
$$

According to equations (7) and (11), we have

$$
\begin{aligned}
& d \widetilde{\tau}_{i}=\frac{\partial \widetilde{\tau}_{i}}{\partial \delta_{i}} d \delta_{i}+\frac{\partial \widetilde{\tau}_{i}}{\partial \omega} d \omega \\
& d G_{i}=\frac{\partial G_{i}}{\partial \delta_{i}} d \delta_{i}
\end{aligned}
$$

Substituting equations (15) and (16) into equation (14), the incremental damage evolution law can be derived as

$$
d \omega=-\sum_{i=1}^{2}\left(\frac{\partial F}{\partial \widetilde{\tau}_{i}} \frac{\partial \widetilde{\tau}_{i}}{\partial \delta_{i}}+\frac{\partial F}{\partial G_{i}} \frac{\partial G_{i}}{\partial \delta_{i}}\right) d \delta_{i} / \sum_{i=1}^{2} \frac{\partial F}{\partial \widetilde{\tau}_{i}} \frac{\partial \widetilde{\tau}_{i}}{\partial \omega}
$$

The damage parameter $\omega$ is updated by the above incremental evolution law in terms of the incremental separations $d \delta_{i}$ until $\omega$ climbs to unity after $f_{g}=1$ is reached. A very small separation increment can guarantee a quite accurate solution. However, relatively large increments can be used for practical structural analysis. A large separation increment passed into the cohesive zone model can be divided into many small increments and the damage parameter is then computed inside the cohesive zone model incrementally to achieve an accurate result.

Now consider the case that the interface is under through-thickness compression and cohesive damage occurs due to shear loading. The problem under this circumstance is a mode II fracture. When there is an increase $d \delta_{2}$ in the shear separation, damage grows by $d \omega$ and 
the cohesive traction-separation moves from point $B$ to point $C$ on the traction-separation curve as shown in Fig. 1. The damaged part in the REA of the interface increases its area by $d A$. In the illustration of the REA in Fig. $1, \omega$ should be replaced by a different parameter $A$ for the present analysis. During this process, the energy dissipated, $d U_{2}$, by the REA equals the area of triangle $O B C$ in Fig. 1. Using the cohesive traction-separation law, $d U_{2}$ can be obtained as

$$
d U_{2} \approx \frac{1}{2} k_{2}\left(\delta_{2}+0.5 d \delta_{2}\right)^{2} d \omega
$$

Based on the energy concept in fracture mechanics, we also have

$$
d U_{2}=d A \times G_{2 c n}
$$

Therefore

$$
d A=\frac{k_{2}\left(\delta_{2}+0.5 d \delta_{2}\right)^{2}}{2 G_{2 c n}} d \omega
$$

$d \omega$ is obtained by using equation (17). $A$, the damaged area in REA of the interface, is updated incrementally according to the above equation in terms of the incremental separations until $A$ (and $\omega$ as well) climbs to unity after decohesion is fully completed.

Friction takes place on the damaged part in the REA of the interface. Although friction does not affect the cohesive behaviour of the interface, it resists the sliding deformation of the interface. The frictional stress is added to the cohesive shear traction of the interface to reflect this effect. A cohesive damage and friction coupled interface model is finally constructed as follows

$$
\begin{array}{ll}
\tau_{1}=\widetilde{\tau}_{1} & \\
\tau_{2}=\widetilde{\tau}_{2} & \text { when } \delta_{1}>0 \\
\tau_{2}=\tau_{2}+A \tau_{f} & \text { when } \delta_{1}<0
\end{array}
$$

where $\tau_{i}(i=1,2)$ are the total tractions on the interface. Cohesive tractions $\tilde{\tau}_{i}$ are defined by 
equation (7) and frictional stress $\tau_{f}$ defined by equation (2).

Different from the coupling method used by Alfano and Sacco[11], Zou and Lee [18] and others $[13,14]$, the damage parameter $\omega$ in the present model represents the cohesive stiffness reduction factor only. The area of the damaged part in the REA of the interface is determined by the cohesive energy release rate based on the energy concept of fracture mechanics. It is related to the damage parameter in the form shown in equation (20). A novel and more physically sound approach is therefore established to combine damage and friction in the cohesive interface model.

The behaviour of the new damage/friction coupled cohesive interface model under constant through thickness compression is shown in Fig. 4 for interface with different stiffness $k_{2}$. It is clear that the peak traction on the curve is not affected by the change of $k_{2}$. The curves converge when $k_{2}$ is moderately high, resulting in a converged energy absorption. Fig. 5 shows the growth of the damaged area in the REA of the interface and the effect of $k_{2}$ on the damage area growth. Unlike the evolution of the damage parameter $\omega$ shown in Fig. 2, the damaged area $A$ grows at a constant rate during the decohesion process. $A$ is smaller than $\omega$, particularly in the early stage of decohesion. The growth curves converge when $k_{2}$ reaches a moderately high value. The use of this realistic damaged area adds the frictional stress to the cohesive shear stress steadily. A better coupling of damage and friction in the cohesive interface model is achieved.

Fig. 6 shows how the shear strength enhancement and friction affect the shear stresssliding separation curve under a constant through thickness compression. The bilinear traction-separation relationship is reproduced when friction $(\mu=0)$ is not considered. The first curve $(\eta=0, \mu=0)$ and the second $(\eta=0.3, \mu=0)$ represent the cohesive shear tractionseparation laws without and with shear strength enhancement, respectively. The third curve $(\eta=0.3, \mu=0.26)$ is the total shear traction-separation law of the interface after the frictional 
stress is added to the cohesive shear traction. The total shear traction-separation curve has three linear parts in general. The shear traction climbs up to an elastic limit at $\tau_{2}=\tau_{2 \mathrm{c}}-\eta \tau_{1}$ where damage initiation starts. Then shear traction decreases continuously until full cohesive failure is reached. After the formation of the crack, only the friction term with a constant value is left in the final region where post damage friction exists.

From these curves, the total increase in mode II fracture energy due to the throughthickness compression during the decohesion process can be estimated as

$$
\Delta G_{2 c}=\frac{1}{2} \eta\left|\tau_{1}\right| \delta_{2 f}+\frac{1}{2} \mu\left|\tau_{1}\right|\left(\delta_{2 f}-\delta_{2 o n}\right) \approx \frac{1}{2}(\eta+\mu)\left|\tau_{1}\right| \delta_{2 f}=(\eta+\mu) \frac{\left|\tau_{1}\right|}{\tau_{2 c}} G_{2 c}
$$

More energy will also be dissipated by the post-decohesion friction. The amount of dissipated energy will depend on the practical problem and structure analysis is required.

The behaviours of this model in the case of $(\eta \neq 0, \mu=0)$ and $(\eta \neq 0, \mu \neq 0)$ are similar to the model (b) and model (c) proposed by Li et al. in [25], respectively. However, the interface model (c) in [25] does not consider the post decohesion friction which may play an important role in improving fracture resistance. The fibre push out test conducted by Tanoglu et al. [26] shows that a significant amount of energy is absorbed by the frictional fibre sliding after a complete fibre/matrix debonding.

\section{Modelling the shear failure of a double-notch composite specimen}

The present damage/friction coupled cohesive interface model and the one developed by Alfano and Sacco [11] have been implemented in ABAQUS as User Material for its Cohesive Element. To validate the present model and demonstrate the advantage of the present damage/friction coupling approach over the existing coupling methods in $[11,12]$, the shear failure test of a symmetric double-notch specimen in [5] was simulated and the predictions were compared to the experiment results.

Fig. 7 shows the specimen and the main features of the test. The specimen has a layup of 
$\left[(0 / 90 / 0)_{4} / 0 /(0 / 90 / 0)_{4}\right]_{\mathrm{S}}$ and a nominal ply thickness of $0.125 \mathrm{~mm}$. The depth of the notch equals a quarter of the thickness of the specimen. In the experiment, a pair of steel indenters was used to apply a compressive load $P$ on the specimen to create a through thickness compression in the gauge section. Longitudinal tension was then applied to the specimen. The final failure of the specimen was caused by the shear failure along the shear planes (indicated by the dotted lines in Fig. 7) in the gauge section under moderate through-thickness compression [5].

A 2D FE simulation of the test was carried out in ABAQUS. Generalised plane strain elements CPEG4 were used to mesh the plies and the steel indenter, with no constraint in the width direction. Cohesive elements $\mathrm{COH} 2 \mathrm{D} 4$ were placed along the shear planes in the gauge section and along the interfaces outside the gauge section at the same height as the shear planes. Sufficiently fine mesh was used, $0.0625 \mathrm{~mm} \times 0.0625 \mathrm{~mm}$ for the solid elements and $0.0625 \mathrm{~mm}$ long for the cohesive elements. Similar to the FE simulation in [5], a frictionless surface to surface contact was defined between the steel indenter and the specimen. The ply material properties are given in Table 2 and the properties for the cohesive interface are shown in Table 1 . The steel has the properties of $E=210 \mathrm{GPa}$ and $v=0.3$.

Alfano and Sacco's cohesive zone model [11] was first employed and interface stiffness $k_{2}$ was attempted over a wide range of values. The numerical load-displacement curves for the specimen are presented in Fig. 8 alongside the experimental measurement. The experimental displacement includes all of the deformations of the specimen, extension rods and test machine [5]. To make the results comparable, the numerical displacements have been scaled to match the initial elastic slope of the experimental curve. When friction is excluded (by setting $\mu=0$, so that the model becomes the traditional cohesive model), the numerical results are independent of $k_{2}$ over the range of values used as expected. However, the predicted final failure load of the specimen is much lower than the load measured in the 
experiment. The inclusion of friction $(\mu=0.26)$ in the model produces a much improved prediction. The load plateaus on the numerical curves are close to the load drop on the experimental curve. This load drop/plateau is caused by the delamination initiation and propagation along the interface outside the gauge section, the same as what was observed in experiment [5]. However, the predicted final failure load is now interface stiffness dependent. The higher the $k_{2}$, the higher the predicted final failure load. The prediction converges when $k_{2}$ is extremely high $\left(k_{2}=1.67 \times 10^{16} \mathrm{~N} / \mathrm{m}^{3}\right)$. The converged final failure load is about $20 \%$ lower than the experimental average.

The surface-based cohesive model in ABAQUS [12] was then employed with friction considered. Cohesive contact surfaces were defined instead of cohesive elements in the FE model for this purpose. The predictions shown in Fig. 9 are similar to those obtained from Alfano and Sacco's model, but giving higher plateaus on the load-displacement curves.

Alfano and Sacco's cohesive model and the surface-based cohesive model in ABAQUS use different methods to determine the damage evolution law. The two models show identical behaviour under single mode loading, a similar behaviour under mixed mode loading with a constant mixed-mode ratio, but a quite different behaviour under variable mixed-mode ratio. The plateaus on the load-displacement curves in Figs. 8 and 9 are caused by the delamination propagation along the interface outside the gauge section. This delamination propagation is a mixed mode fracture and the mixed-mode ratio varies during the decohesion of the cohesive interface. Results show that in this case, the surface-based cohesive model in ABAQUS produces a slower damage evolution rate than Alfano and Sacco's cohesive model and requires more energy for the delamination propagation. Higher plateaus on the loaddisplacement curves are thus produced by the surface-based cohesive model in ABAQUS. However, the final failure of the specimen is caused by the delamination in the gauge section where the interface is under through-thickness compression and the problem is a pure mode II 
delamination. The predicted final failure loads of the specimen from these two models are therefore almost the same as indicated in Figs. 8 and 9.

Finally, the present damage/friction coupled cohesive interface model was adopted and the numerical load-displacement curves are shown in Fig. 10. The converged prediction matches the experiment closely, both for the load plateau/drop and the final failure load. More importantly, the predicted results already converge at a moderately high interface stiffness $k_{2}=1.67 \times 10^{14} \mathrm{~N} / \mathrm{m}^{3}$.

To summarise, the present damage/friction coupled model produces interface stiffness independent results once the interface is moderately stiff. In contrast, the predictions obtained from the existing coupled models are extremely interface stiffness dependent. This clearly demonstrates the advantage of the present damage/friction coupling method over its counterparts in [11] and [12]. Comparing the predictions to the experiment, the present model produces a better prediction of the final failure load than the existing models.

To make the experimental results more meaningful, an average shear strength of the specimen was defined by Gan et al. [5] as the ratio between the final tensile failure load and the total shear failure area of the gauge section. The severity of the through thickness compression was represented by the average through thickness compressive stress over the gauge length which can be determined from the finite element analysis after the application of compression load $P$ is completed. The effect of through thickness compression on the shear strength of the specimen is shown in Fig. 11, obtained experimentally [5] and numerically from the present model. It can be seen that there is a good agreement between the numerical and experimental results at all compression levels when the interface properties in Table 1 are used. The numerical predictions $\left(\tau_{2 c}=82.6 \mathrm{MPa}, \eta=0.3\right)$ are just slightly lower than the experimental data, but are quite close to the lower bound of the experimental range.

The baseline shear strength $\tau_{2 c}=82.6 \mathrm{MPa}$ and the enhancement factor $\eta=0.3$ in Table 1 
were determined in [5] by using the least square linear fit of equation (8), i.e. $\tau_{2 c n}=\tau_{2 c}-\eta \widetilde{\tau}_{1}$, to the experimental average shear strengths of the specimen under different through-thickness compression levels. This method is accurate but only when the shear stress distributes uniformly along the shear plane of the specimen. However, a uniform distribution of the shear stress in this notched specimen does not exist. Stress concentration at the notches causes damage there first, which subsequently reduces the initially high stress to a low level as damage grows.

The predicted stresses and damage status along the shear plane of the specimen immediately before the final failure are shown in Fig. 12. The through thickness compressive stress is reasonably uniform over the gauge section. However, the shear stresses are not uniform at all. Damage has occurred on the interface over most of the gauge section. No part has reached the full failure status, although damage has developed most at the notches. The shear stress $\tau_{2}$ on the damaged interface has dropped from its peak value. The average shear stress over the gauge section is about $10 \%$ lower than the maximum value at the position where the damage just initiates. This indicates that the maximum shear stress $\tau_{2 c n}=\tau_{2 c}-\eta \widetilde{\tau}_{1}$ on the interface is higher than the average shear strength of the specimen determined in [5]. The real values of $\tau_{2 c}$ and $\eta$ should be slightly higher than those in Table 1.

May and Hallett [27] measured the interlaminar shear strength of the same material using short beam shear test and double notched shear test. The former test produced a shear strength of $103.2 \mathrm{MPa}$ and the latter gave a value of only $82.5 \mathrm{MPa}$. In the present work, a small adjustment was therefore made to raise $\tau_{2 c}$ to $92.85 \mathrm{MPa}$ (i.e. the average of $103.2 \mathrm{MPa}$ and $82.5 \mathrm{MPa}$ ). This $10 \mathrm{MPa}$ increase in $\tau_{2 c}$ improves the shear strength of the specimen by about $5 \mathrm{MPa}$ as shown in Fig. $11\left(\tau_{2 c}=92.85 \mathrm{MPa}, \eta=0.3\right)$. To look into how the prediction is influenced by a small change of the enhancement factor $\eta$, a further $10 \%$ increase in $\eta$ was 
also attempted. As expected, increasing $\eta$ raises the slope of the shear strength-through thickness compressive stress curve $\left(\tau_{2 c}=92.85 \mathrm{MPa}, \eta=0.33\right)$, resulting in a bigger improvement in the shear strength of the specimen when it is under a higher through thickness compression. The $10 \%$ increase in both $\tau_{2 c}$ and $\eta$ generates a $5 \%$ improvement in the shear strength of the specimen, and the improved predictions ( $\left.\tau_{2 c}=92.85 \mathrm{MPa}, \eta=0.33\right)$ are within the experiment range as shown in Fig. 11.

\section{Conclusions}

The reason behind the interface stiffness dependence issue encountered by the interface damage/friction coupled cohesive models in the literature and ABAQUS has been identified for the first time. This issue is caused by the use of a single damage parameter to represent both the cohesive stiffness reduction factor and the damaged area in the REA of the interface. This damage parameter has been proved to be extremely stiffness dependent and provides a physically unrealistic growth of the damaged area in the REA of the interface. Including friction in the cohesive zone model on the basis of this parameter not only creates the stiffness dependence issue, but also significantly over contributes the frictional stress to the shear stress of the interface during the decohesion process, particularly in the early stage of decohesion.

A new damage/friction coupling approach has been established to avoid the interface stiffness dependence issue. Based on the energy concept of fracture mechanics, the damaged area in the REA of the interface is derived. It is simply related to the cohesive energy release rate. A realistic growth of the damaged part in the REA of the interface is obtained and a better combination of interface damage and friction is achieved. The behaviour of the cohesive interface model using the new damage/friction coupling method is interface stiffness independent once the interface becomes moderately stiff.

The new damage/friction coupled cohesive interface model has been validated by its 
application to a shear failure test of a symmetric double notched specimen. The predictions are in good agreement with the experimental results available in the literature.

Although the new energy based approach to couple damage/friction in the present cohesive zone model is formulated in an incremental manner, it is easy and straightforward to combine this energy based approach with other cohesive formulations in the literature that have a closed form damage evolution law such as the one in [11].

\section{References}

[1] Aymerich F, Dore F, Priolo P. Simulation of multiple delaminations in impacted crossply laminates using a finite element model based on cohesive interface elements. Compos Sci Technol 2009;69:1699-1709.

[2] Atas A, Mohamed GF, Soutis C. Modelling delamination onset and growth in pin loaded composite laminates. Compos Sci Technol 2012;72:1096-1101

[3] Tvergaard V. Effect of fibre debonding in a whisker-reinforced metal. Mater Sci Eng 1990;A125(2):203-213.

[4] Ribeiro TEA, Campilho RDSG, da Silva LFM, Goglio L. Damage analysis of composite-aluminium adhesively-bonded single-lap joints. Compos Struct 2016: $136: 25-33$

[5] Gan KW, Hallett SR, Wisnom MR. Measurement and modelling of interlaminar shear strength enhancement under moderate through-thickness compression. Compos Part A Appl Sci Manuf 2013;49:18-25.

[6] Cui W, Wisnom MR, Jones M. Effect of through-thickness tensile and compressive stresses on delamination propagation fracture energy. J Compos Technol Res 1994;16(4):329-335.

[7] Sitnikova E, Li S, Li D, Yi X. Subtle features of delamination in cross-ply laminates due to low speed impact. Compos Sci Technol 2017;149:149-158.

[8] Chaboche JL, Girard R, Schaff A. Numerical analysis of composite systems by using interphase/interface models. Comput Mech 1997;20(1):3-11.

[9] Liu PF, Gu ZP, Peng XQ. A nonlinear cohesive/friction coupled model for shear 
induced delamination of adhesive composite joint. Int J Fract 2016;199:135-156.

[10] Snozzi L, Molinari JF. A cohesive element model for mixed mode loading with frictional contact capability. International Journal for Numerical Methods in Engineering 2013;93(5):510-526.

[11] Alfano G, Sacco E. Combining interface damage and friction in a cohesive-zone model. Int J Nume. Methods Eng 2006;68(5):542-582.

[12] Abaqus 6.14, Analysis user's manual 6.14, 37.1.10. Surface-based cohesive behaviour. Dassault Systemes Simulia Corp., Providence, RI, USA, 2014.

[13] Turon A, Davila CG, Camanho PP, Costa J. An engineering solution for mesh size effects in the simulation of delamination using cohesive zone models. Eng Fract Mech 2007;74:1665-1682.

[14] Zhang J, Zhang X. Simulating low-velocity impact induced delamination in composites by a quasi-static load model with surface-based cohesive contact. Compos Struct $2015 ; 125: 51-57$.

[15] Schön J. Coefficient of friction of composite delamination surfaces. Wear 2000;237(1):77-89.

[16] Parrinello F, Failla B, Borino G. Cohesive-frictional interface constitutive model. Int J Solids Struct 2009;46(13):2680-2692.

[17] van der Meer FP, Sluys LJ. A numerical investigation into the size effect in the transverse crack tension test for mode II delamination. Compos Part A Appl Sci Manuf $2013 ; 54: 145-152$.

[18] Zou Z, Lee H. A cohesive zone model taking account of the effect of through-thickness compression. Compos Part A Appl Sci Manuf 2017;98:90-98.

[19] Zhang C, Curiel-Sosa JL, Bui TQ. A novel interface constitutive model for prediction of stiffness and strength in 3D braided composites. Compos Struct 2017;163:32-43.

[20] Minnicino MA, Santare MH. Modelling the progressive damage of the micro droplet test using contact surfaces with cohesive behaviour, Compos. Sci. Technol. 2012;72:2024-2031.

[21] Sharma R, Mahajane P, Mittal RK. Fiber bundle push-out test and image-based finite element simulation for 3D carbon/carbon composites. Carbon 2012;50:2717-2725. 
[22] Bao H, Liu G. Progressive failure analysis on scaled open-hole tensile composite laminates. Compos Struct 2016;150:173-180.

[23] Hou JP, Petrinic N, Ruiz C. A delamination criterion for laminated composites under low-velocity impact. Compos Sci Technol 2001;61(14):2069-2074.

[24] Christensen RM, Deteresa SJ. Delamination failure investigation for out-of-plane loading in laminates. J Compos Mater 2004;38(24):2231-2238.

[25] Li X, Hallet SR, Wisnom MR. Predicting the effect of through-thickness compressive stress on delamination using interface elements. Compos Part A Appl Sci Manuf 2008;39(2):218-230.

[26] Tanoglu M, McKnight SH, Palmese GR, Gillespie Jr JW. The effects of glass-fiber sizings on the strength and energy absorption of the fiber/matrix interphase under high loading rates. Compos Sci Technol 2001;61:205-220.

[27] May M, Hallett SR. An assessment of through-thickness shear tests for initiation of fatigue failure. Compos Part A Appl Sci Manuf 2010;41:1570-1578. 
Table 1 Interface material properties for IM7/8552 UD ply [5, 18$]$

\begin{tabular}{|c|c|c|c|c|c|c|c|}
\hline$\tau_{1 \mathrm{c}}(\mathrm{MPa})$ & $\tau_{2 \mathrm{c}}(\mathrm{MPa})$ & $k_{1}\left(\mathrm{~N} / \mathrm{m}^{3}\right)$ & $k_{2}\left(\mathrm{~N} / \mathrm{m}^{3}\right)$ & $G_{I C}\left(\mathrm{~J} / \mathrm{m}^{2}\right)$ & $G_{I I C}\left(\mathrm{~J} / \mathrm{m}^{2}\right)$ & $\mu$ & $\eta$ \\
\hline 60 & 82.6 & $4.67 \times 10^{14}$ & $1.67 \times 10^{14}$ & 200 & 1000 & 0.26 & 0.3 \\
\hline
\end{tabular}

Table 2 Material properties for IM7/8552 UD ply [5]

\begin{tabular}{|c|c|c|c|}
\hline$E_{1}(\mathrm{GPa})$ & $E_{2}(\mathrm{GPa})$ & $G_{12}(\mathrm{GPa})$ & $v_{12}$ \\
\hline 161 & 11.4 & 5.17 & 0.32 \\
\hline
\end{tabular}




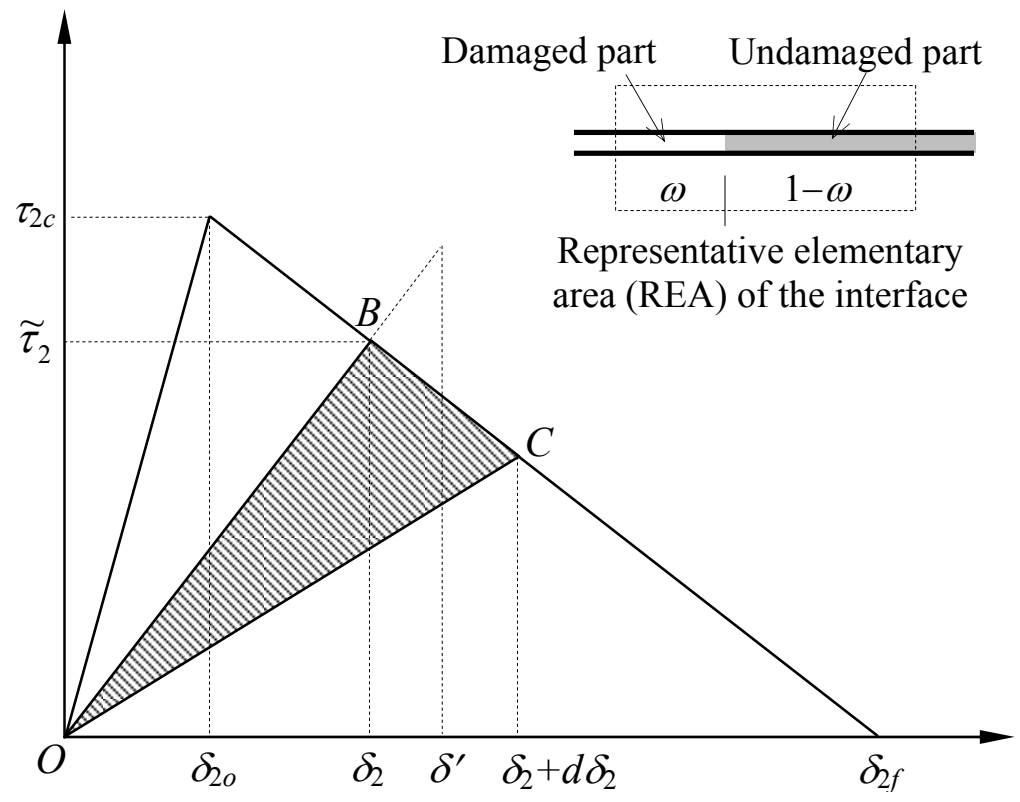

Figure 1 Representative interface element and the bilinear cohesive traction-separation law

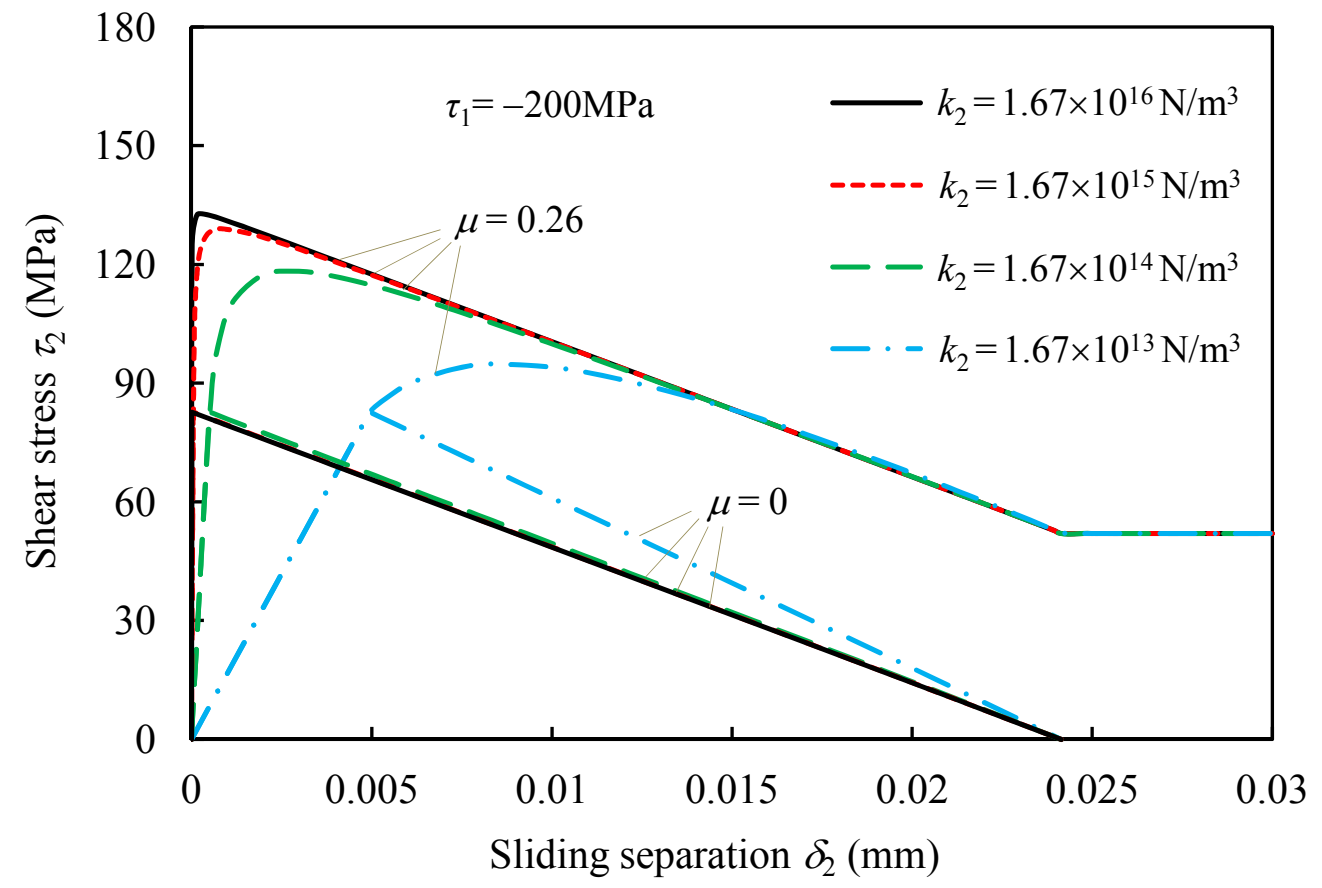

Figure 2 Effect of the interface stiffness $k_{2}$ on the shear stress-sliding separation curve obtained from the damage/friction coupled cohesive zone model in [11] 


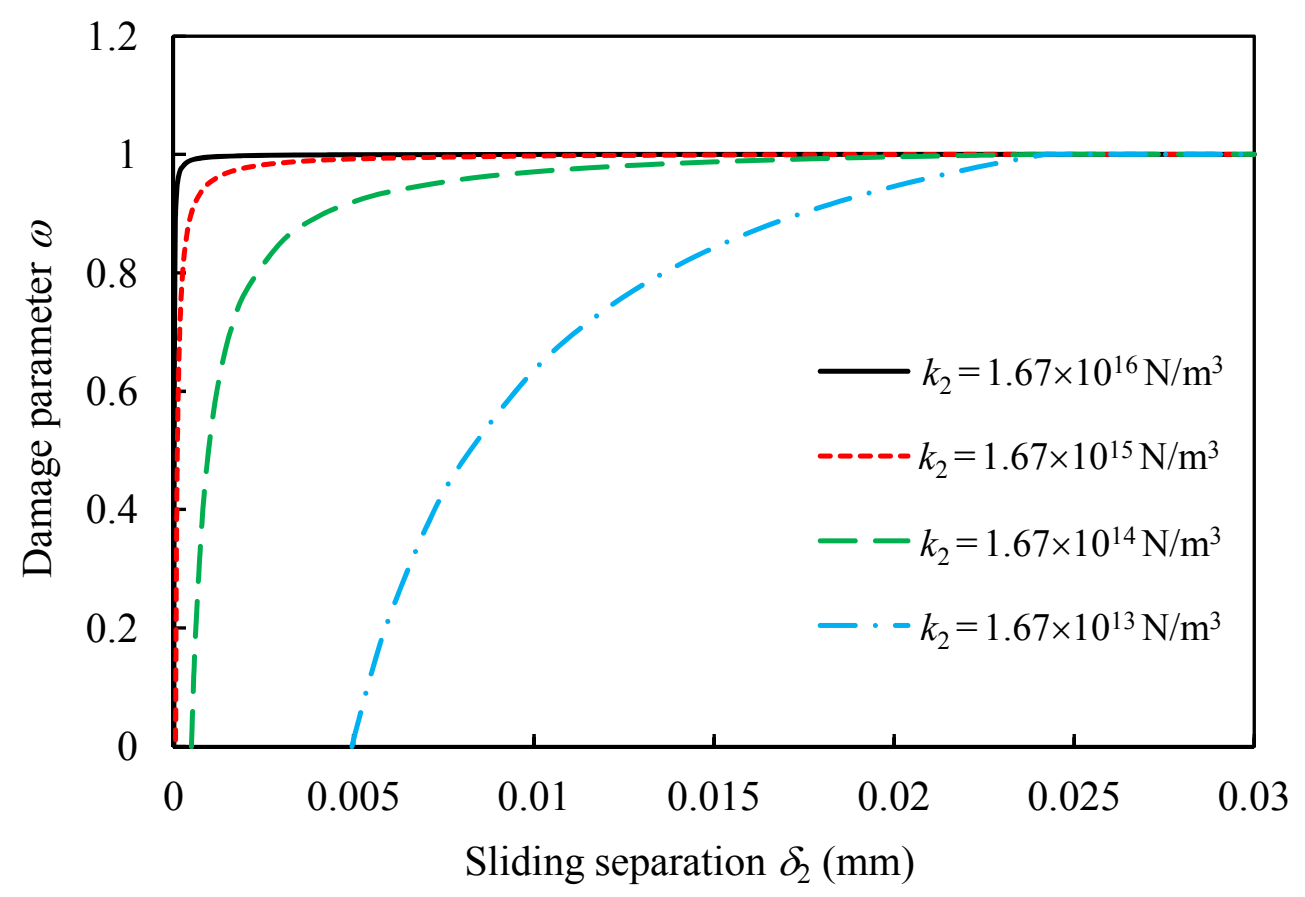

Figure 3 Effect of the interface stiffness $k_{2}$ on damage evolution

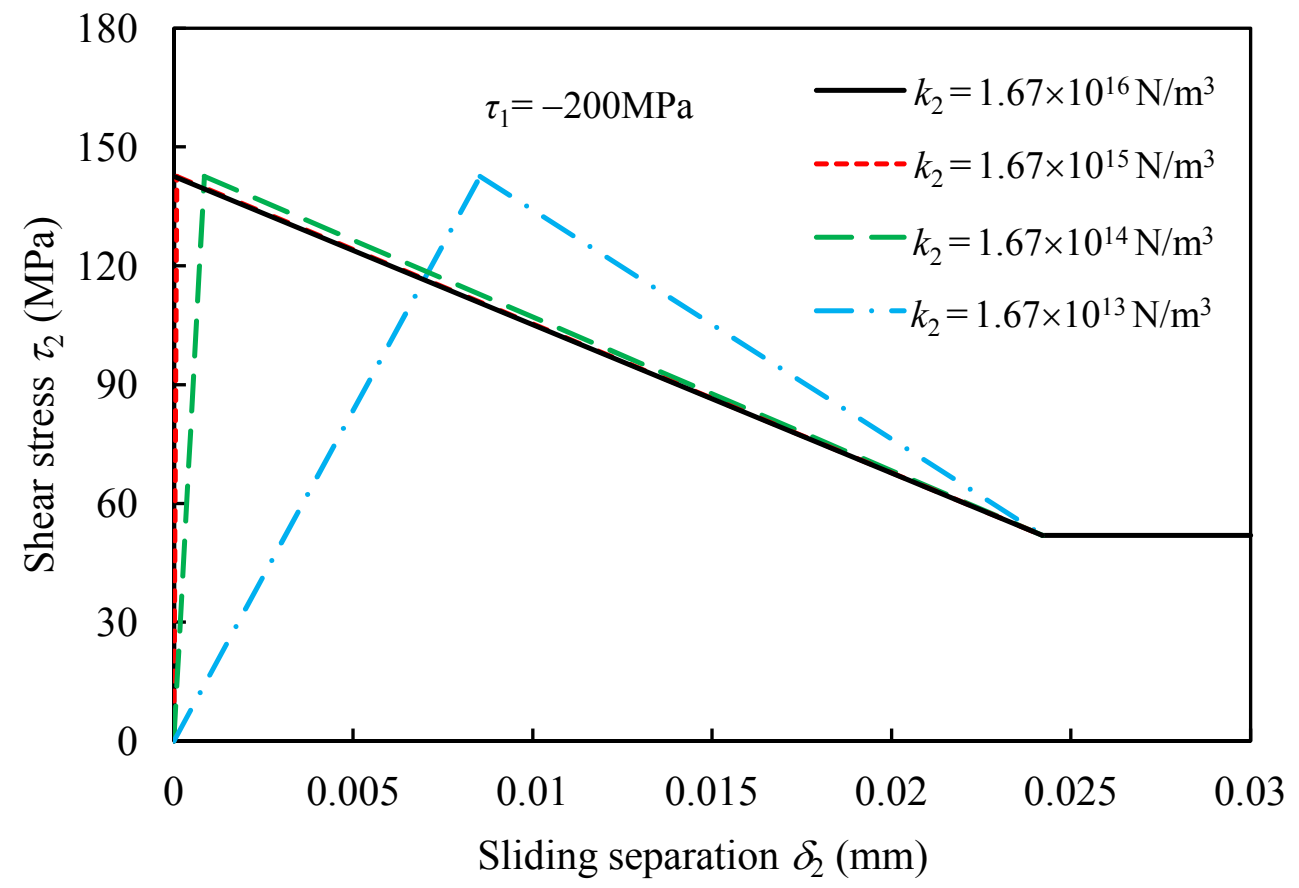

Figure 4 Effect of the interface stiffness $k_{2}$ on the shear stress-sliding separation curve obtained from the present damage/friction coupled cohesive interface model 


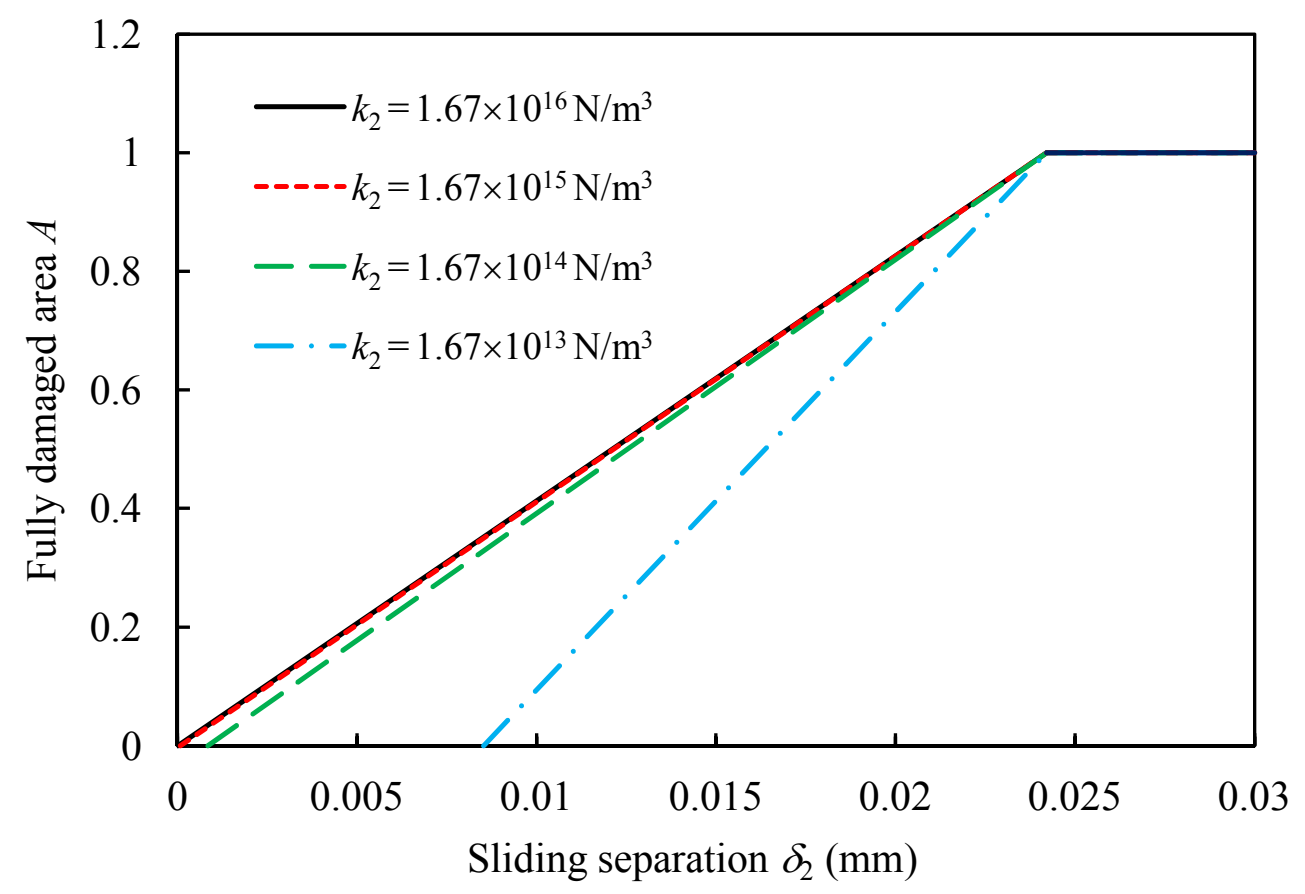

Figure 5 Effect of the interface stiffness $k_{2}$ on the growth of the damaged area $A$ in the representative elementary area of the interface

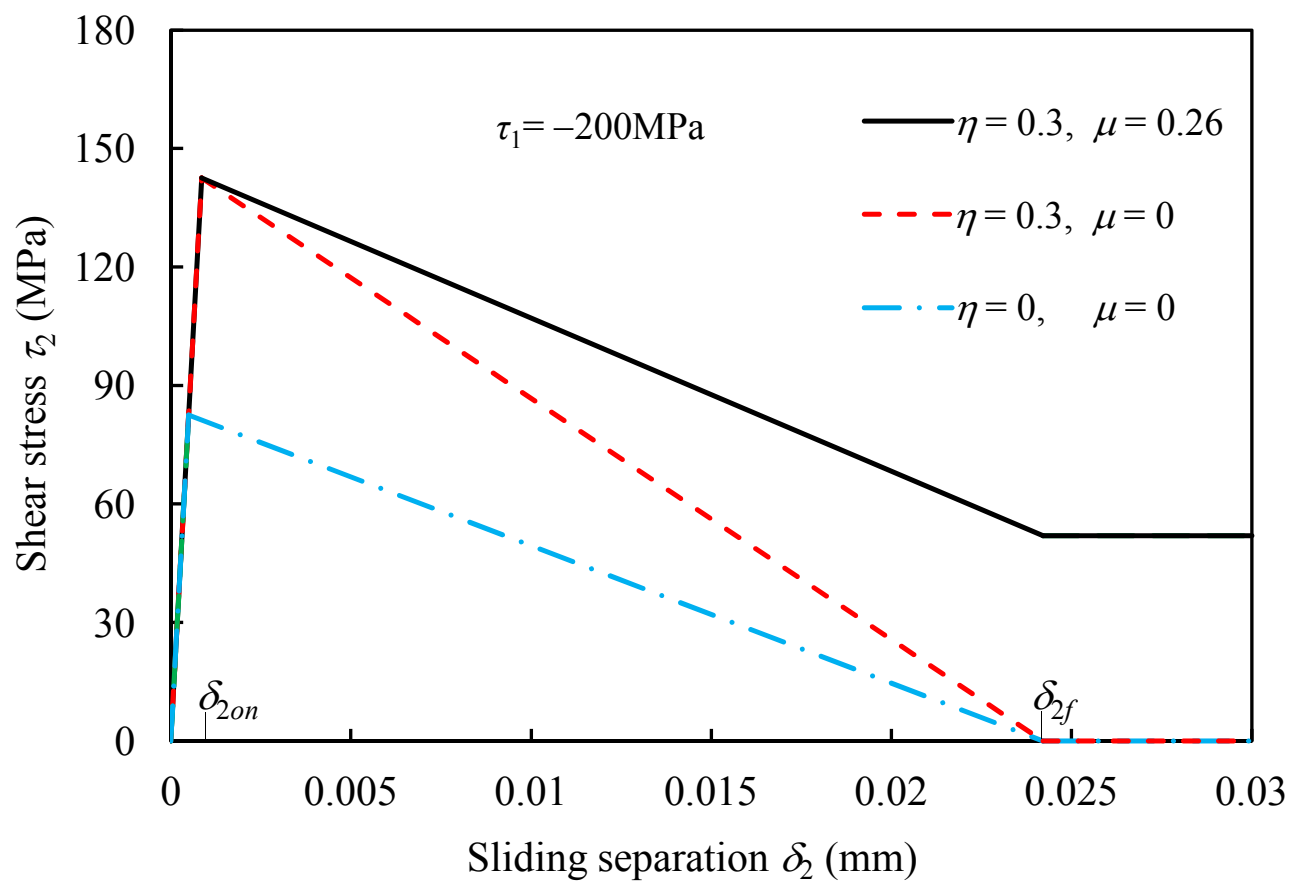

Figure 6 Effect of the shear strength enhancement and friction on the shear stress-sliding separation curve of the interface (through-thickness stress $=-200 \mathrm{MPa}$ ) 

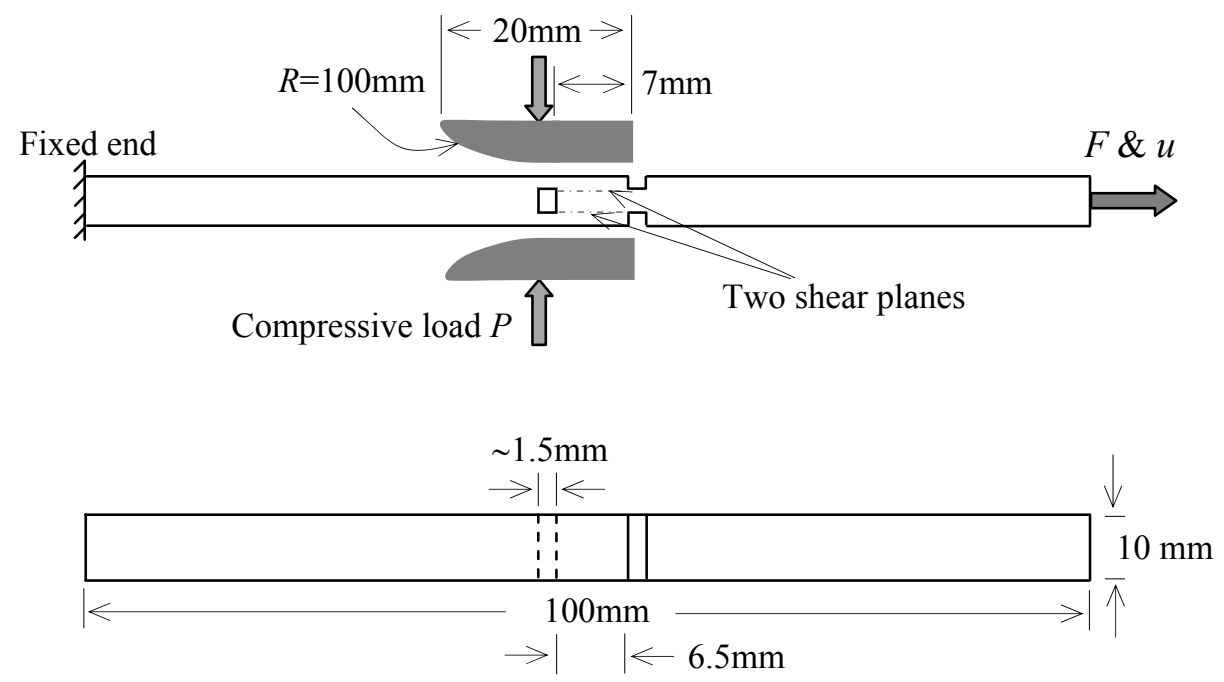

Figure 7 Schematic representation of the symmetric double-notch shear specimen (side and top view, only the untabbed section shown, not to scale) [5]

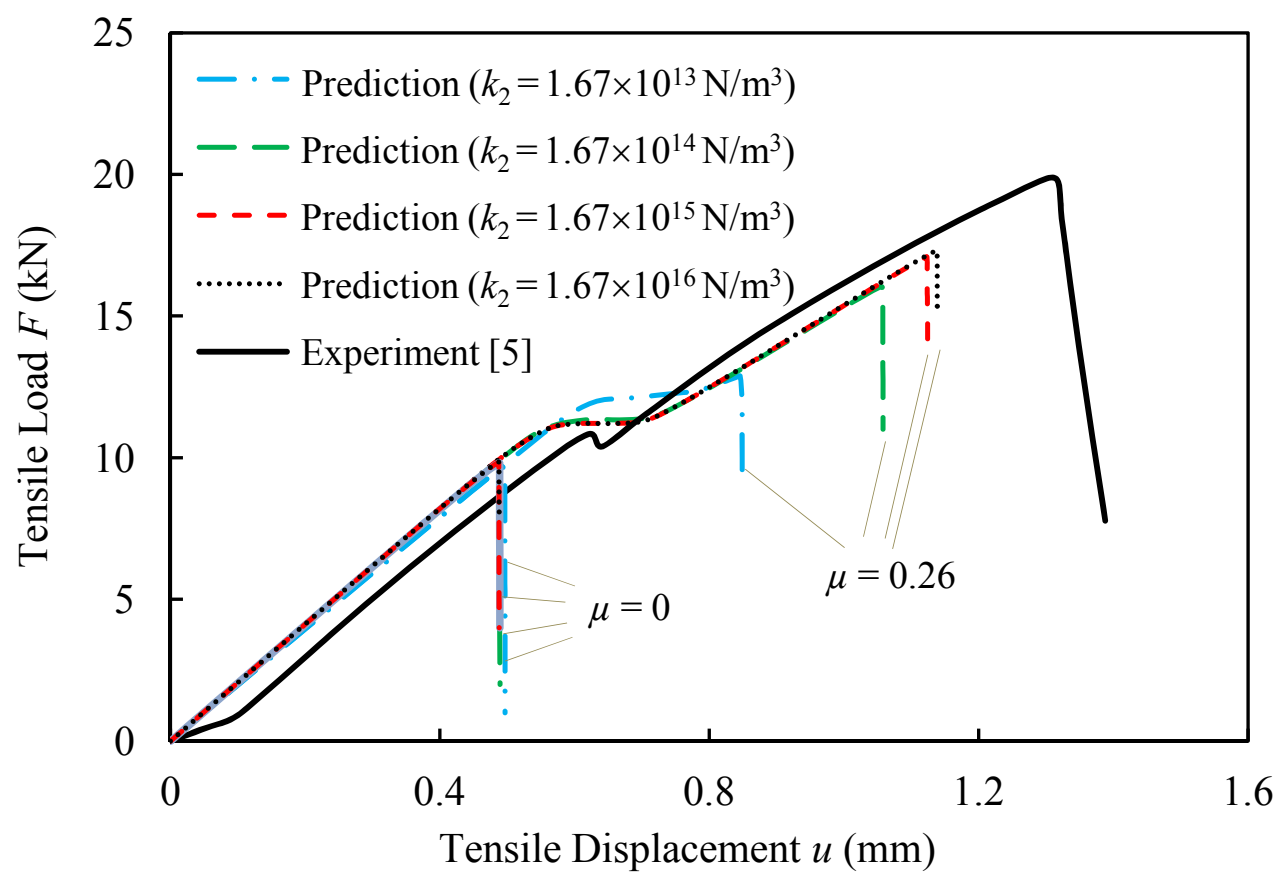

Figure 8 Tensile load-displacement curves of the specimen at $P=20 \mathrm{kN}$ (The cohesive zone model in [11] was used) 


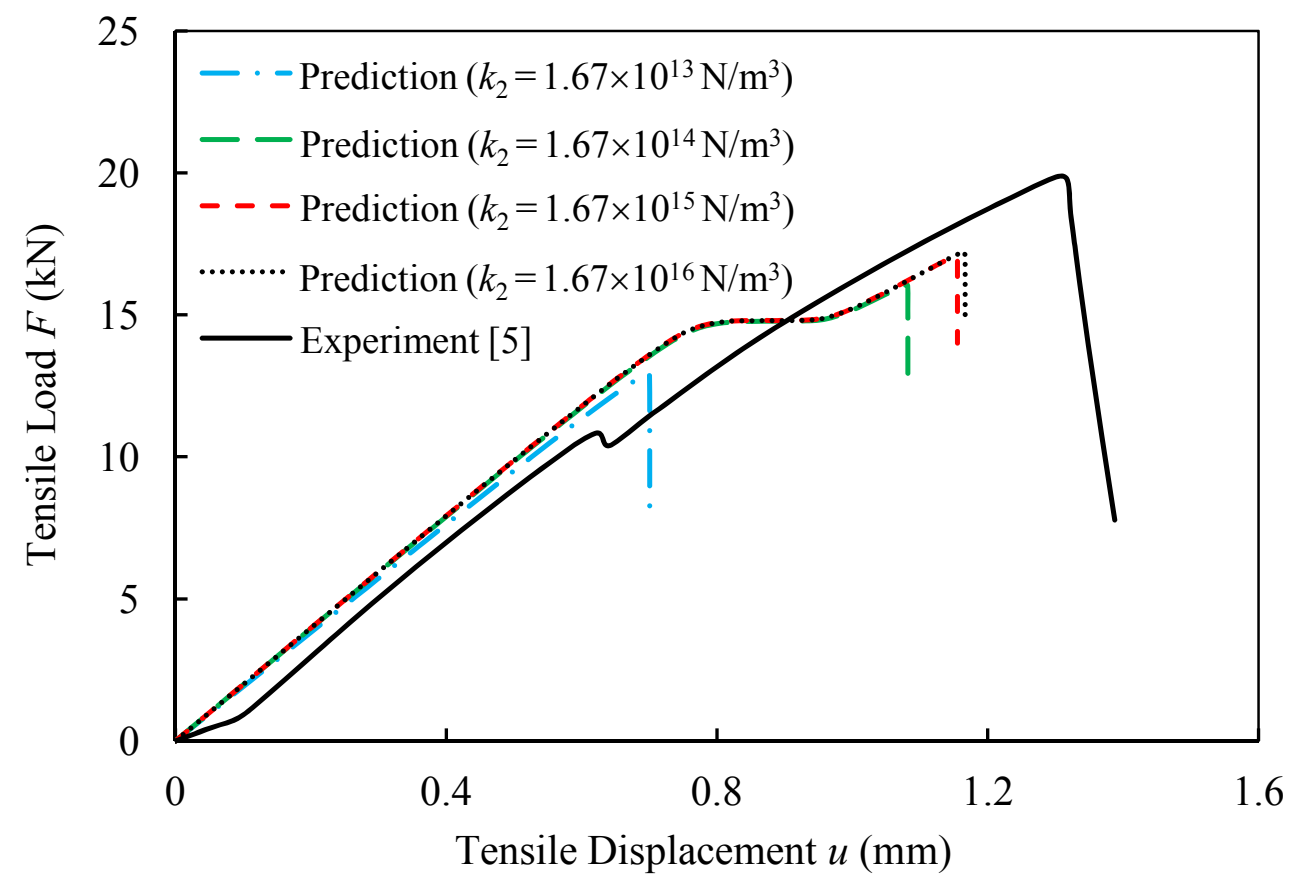

Figure 9 Tensile load-displacement curves of the specimen at $P=20 \mathrm{kN}$ (The surface-based cohesive model in ABAQUS [12] was used)

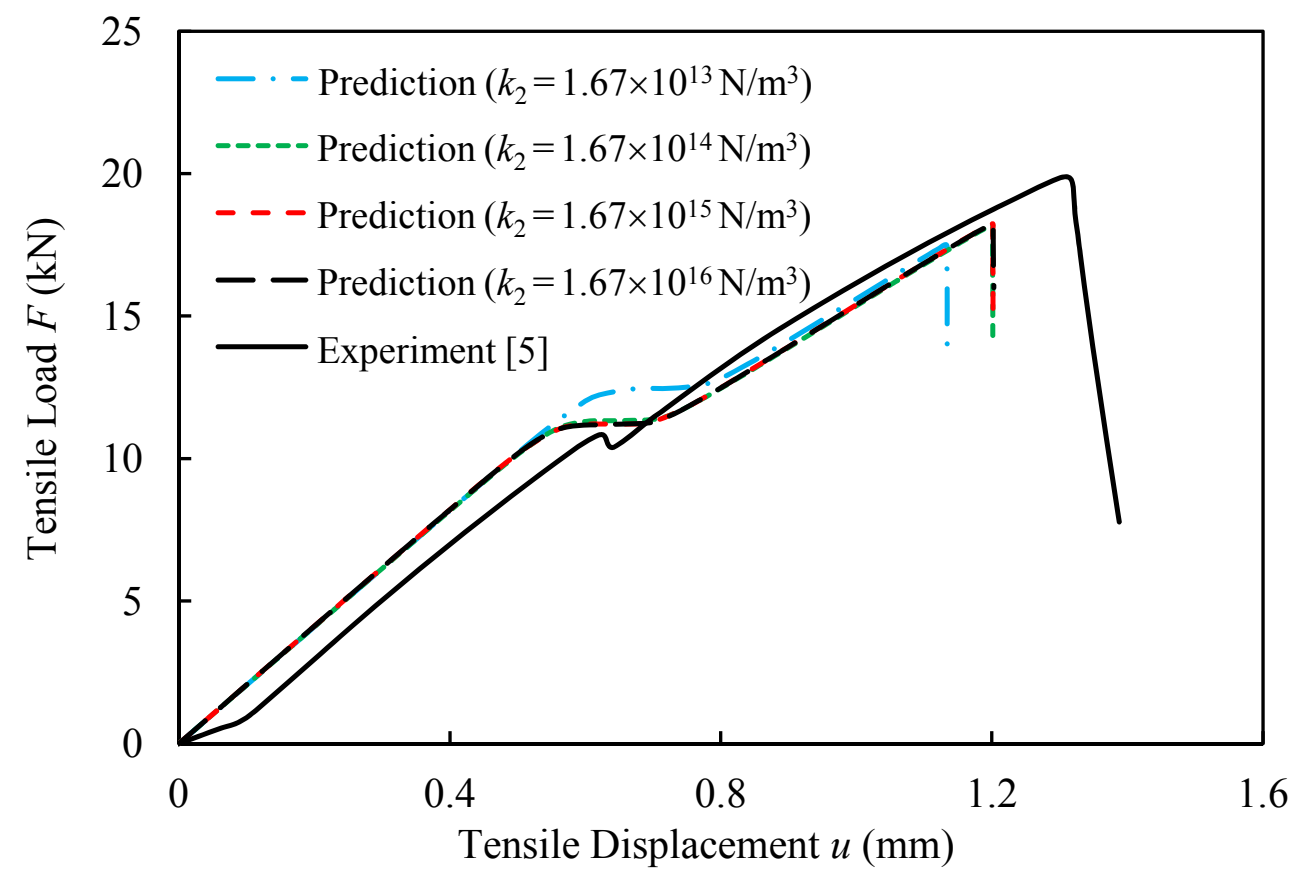

Figure 10 Tensile load-displacement curves of the specimen at $P=20 \mathrm{kN}$ (The present damage/friction coupled cohesive interface model was used) 


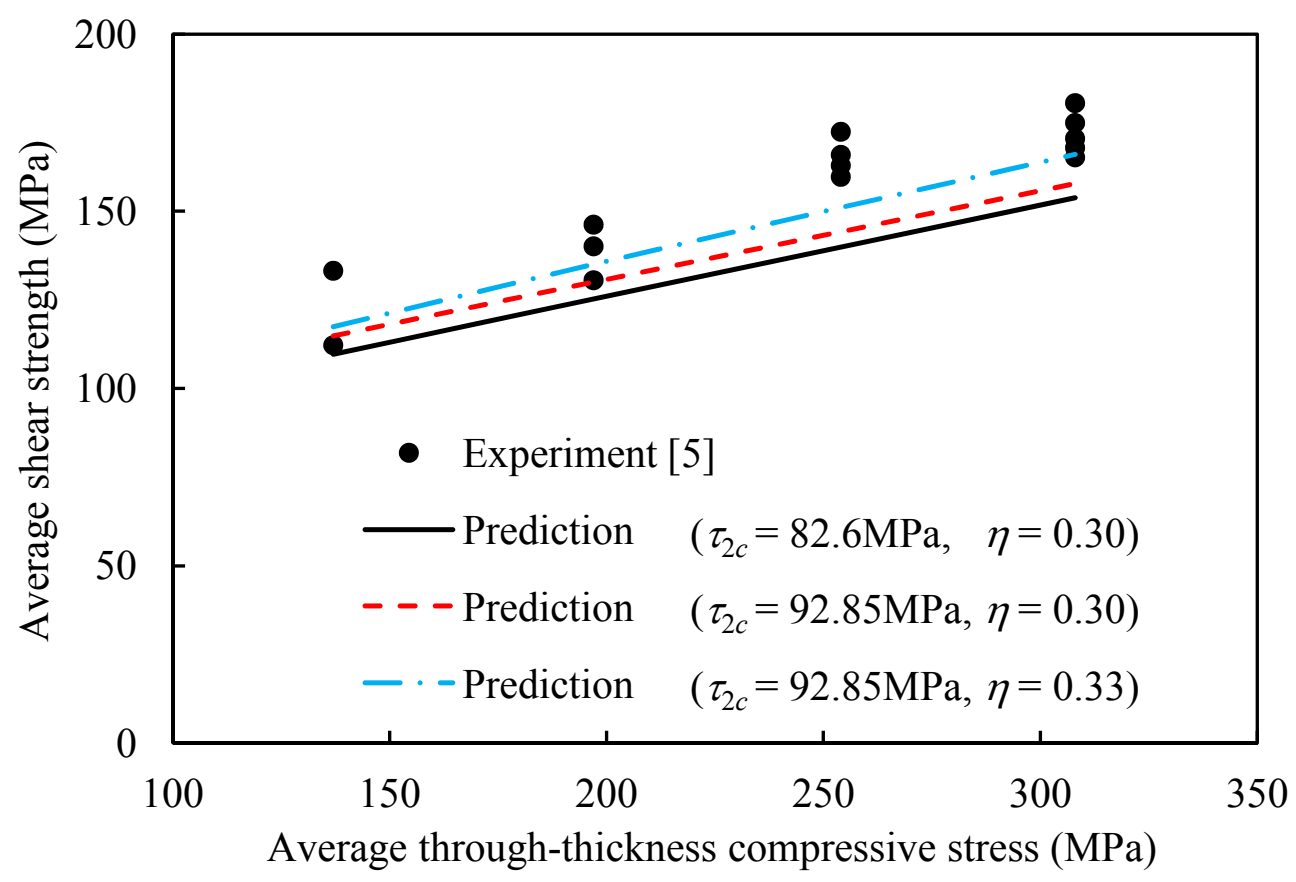

Figure 11 Experimental and FE predicted average shear strength of the specimen under different levels of through-thickness compression

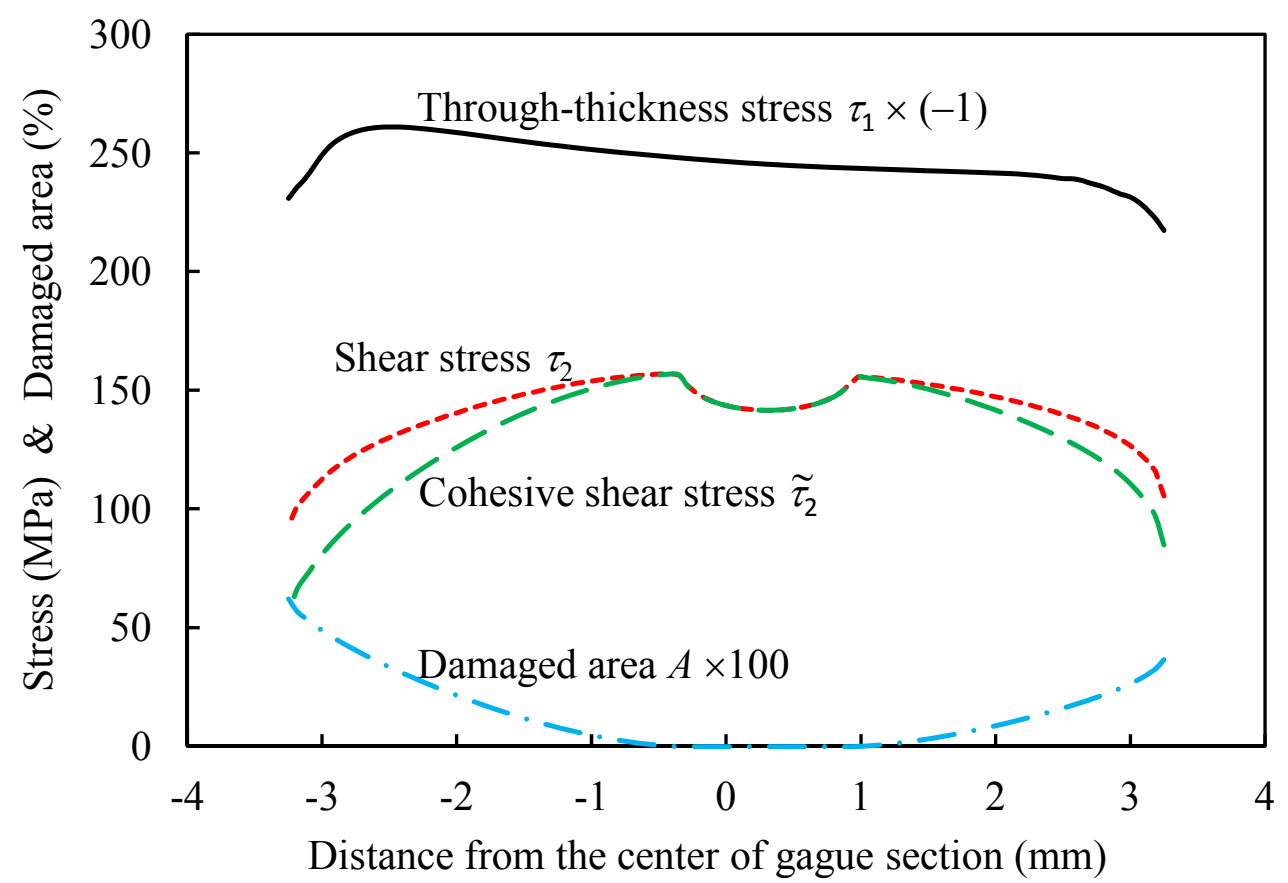

Figure 12 Distributions of tractions and damaged area along the interface in the gauge section immediately before final failure $(P=20 \mathrm{kN})$ 